\title{
Long-Time Creep in a Pure-Gum Rubber Vulcanizate: Influence of Humidity and Atmospheric Oxygen*
}

\author{
Lawrence A. Wood, George W. Bullman, and Frank L. Roth** \\ Institute for Materials Research, National Bureau of Standards, Washington, D.C. 20234
}

(June, 14, 1974)

\begin{abstract}
Long-time creep of natural rubber cured with a sulfur-accelerator recipe containing no filler can be conveniently represented by a plot of $\left(E-E_{1}\right) / E_{1}=\Delta E / E_{1}$ with a double-abscissa scale showing $\log t$ and $t . E$ is the elongation at any time $t$, after application of the load, and $E_{1}$ its value at unit time. Experimental data conform to the equation
\end{abstract}

$$
\Delta E / E_{1}=A \log t+B(t-1)
$$

except for a more rapid rise preceding rupture. The constants $A$ and $B$ can be evaluated from only three observations - at the longest time (about 70 days), at one minute, and at an intermediate time. $\Delta E / E_{1}$ is approximately linear with $\log t$ when $t$ is less than $0.1(A / B)$ and approximately linear with $t$ when $t$ is greater than $4.343(A / B)$. The observed modulus was about $1.4 \mathrm{MPa}$ and $A$ was about 2.4 percent/(unit $\log t)$ when the atmosphere was a vacuum, dry $\mathrm{N}_{2}$, or dry air. The modulus was lowered very slightly and $A$ became about 4 percent/(unit $\log t$ ) when the air was saturated with water. $B$ was raised from about $2 \times 10^{-5}$ percent $/ \mathrm{min}$ to about $20 \times 10^{-5}$ percent $/ \mathrm{min}$ when the vacuum or dry $\mathrm{N}_{2}$ was replaced by dry air and to about $50 \times 10^{-5}$ percent $/ \mathrm{min}$ when the air was saturated with moisture. $A$ is considered to be related to physical relaxation, while $B$ corresponds to a chemical reaction, probably oxidative degradation.

Key words: Compliance of rubber; creep, long-time, in rubber; humidity, effect of, on creep of rubber; modulus of rubber, effect of humidity; oxygen, influence of, on creep of rubber; rubber, natural, creep; time, effect of, on compliance of rubber.

\section{Introduction}

Previous studies $[1,2]^{1}$ in the laboratories of the National Bureau of Standards have investigated the compliance of a typical pure-gum rubber compound vulcanized in a conventional sulfur-accelerator system. The range of temperature in those studies was from -60 to $+100{ }^{\circ} \mathrm{C}$, while the time at a given temperature in most cases ranged from $5 \mathrm{~s}$ to $10 \mathrm{~min}$. The present work was undertaken in order to study the compliance at room temperature during time intervals from $1 \mathrm{~min}$ to about $100,000 \mathrm{~min}$ (about 70 days). The effect of ambient humidity and atmospheric oxygen on compliance and creep were given special attention in this study.

\section{Experimental Arrangements}

The recipe used was ASTM Formula 1A in Method 15-59T (formerly called ACS-1 Recipe) as follows:

\footnotetext{
* Presented at: International Symposium on Macromolecules, Rio de Janeiro, BrazilJuly 1974.

** Retired.

${ }^{1}$ Figures in brackets indicate the literature references at the end of this paper.
}

Natural rubber (NBS 385a) 100; Zinc Oxide (NBS 370a) 6; Sulfur (NBS 371b) 3.5; Stearic Acid (NBS 372c) 0.5; and Mercapto-benzothiazole (NBS 383) 0.5 parts by weight. From a flat sheet cured $60 \mathrm{~min}$ at $125{ }^{\circ} \mathrm{C}$ $\left(257^{\circ} \mathrm{F}\right)$ strips were cut with dimensions about $150 \times$ $6.56 \times 0.50 \mathrm{~mm}$. A mass of $257.6 \mathrm{~g}$ was suspended, producing an initial stress of $0.770 \mathrm{MPa}\left(7.85 \mathrm{~kg} / \mathrm{cm}^{2}\right)$ on each specimen. The specimens were marked with gage marks $100 \mathrm{~mm}$ apart. A two-telescope cathetometer was used to measure elongations to the nearest $0.1 \mathrm{~mm}$. Observations were begun 2 or $3 \mathrm{~min}$ after the application of the force and were continued to about $100,000 \mathrm{~min}-$ about 70 days. The temperature and relative humidity of the laboratory were held at $23.5^{\circ} \mathrm{C}$ and 35 percent respectively.

The specimens were contained in glass tubes to permit the attainment of four different conditions as follows:

Specimen A-Conditioned 2 hours in dry nitrogen before test. Dry nitrogen passed through tube during test.

Specimen B-Conditioned 5 weeks in desiccator with $\mathrm{CaCl}_{2}$ before test. Dry air passing over $\mathrm{CaCl}_{2}$ during test. 
Specimen C-Surrounded by laboratory air (35 percent relative humidity) before and during test. No circulation.

Specimen D-Conditioned 5 weeks over water before test. Air bubbled through water during test.

It should be noted that the thickness of the specimens was limited to only $0.50 \mathrm{~mm}$ in order to accentuate the effects of the atmosphere around the specimens and to eliminate diffusion limitations as much as possible.

\section{One-Minute Elongation and Modulus}

In view of the importance of an accurate value of $E_{1}$, the 1-min elongation, in the calculations, this value was determined by plotting the elongation against the logarithm of the time for all observations in the first hundred minutes. In all cases, straight lines were obtained in conformity with literature results (quoted later in this paper) extending to times of the order of milliseconds. Consequently a linear extrapolation of our observations was used to obtain the 1 -min intercept, where $\log t=0$.

The empirical stress-strain equation of Martin, Roth, and Stiehler [3]

$$
F / M=\left(L^{-1}-L^{-2}\right) \exp A\left(L-L^{-1}\right)
$$

was used to calculate the ratio of $F$ (force divided by the cross-sectional area of the unstretched specimen) to Young's Modulus $M$, the slope of the stresselongation curve at zero stress. $L=E+1$ is the ratio of stressed length to unstressed length, where $E$ is the elongation. The constant $A$ is 0.38 . The 1-min. modulus $M_{1}$ was then calculated from the ratio $F / M$ and $F=0.770 \mathrm{MPa}\left(7.85 \mathrm{~kg} / \mathrm{cm}^{2}\right)$ obtained from the force and the cross-sectional area of the unstretched specimen. The results are given in table 1 . It is concluded that the oxygen content of the atmosphere surrounding the specimens has very little effect on the 1-min modulus. The modulus appears to be lowered slightly at the highest humidity but the change is small.

TABLE 1

\begin{tabular}{c|c|c|c|c}
\hline \hline Specimen & A & B & C & D \\
\hline Atmosphere & $\mathrm{N}_{2}$ & Air & Air & Air \\
\hline Relative Humidity & & & & \\
$\% \ldots$ & very low & very low & 35 & 100 \\
$E_{1} \ldots \ldots \ldots \ldots \ldots \ldots \% \ldots$ & 144.7 & 144.7 & 146.2 & 153.6 \\
$F / M \ldots \ldots \ldots \ldots \ldots \ldots \ldots$. & 0.5243 & 0.5243 & 0.5272 & 0.5386 \\
$M_{1} \ldots \ldots \ldots \ldots \ldots . \ldots \ldots \ldots$ & 1.469 & 1.469 & 1.461 & 1.430 \\
\hline
\end{tabular}

The decrease in modulus at 100 percent relative humidity was somewhat less than the 3.5 percent decrease reported by Derham [4] as the relative humidity was increased from 20 to 80 percent.

In the present work, it has been found convenient to express the results in terms of the fractional creep
$\Delta E / E_{1}$ where $E_{1}$ is the elongation at 1-min, $E$ the elongation at a later time, and $\Delta E=E-E_{1}$. The modulus or compliance at any time can be calculated, if desired, from the elongation and the stress by the method just used to calculate the 1-min modulus.

\section{Results of Creep Experiments}

It is convenient to present the creep results in the form of a double-abscissa plot like figure 1. Here $t$ is the time during which the load is applied, and the frac-

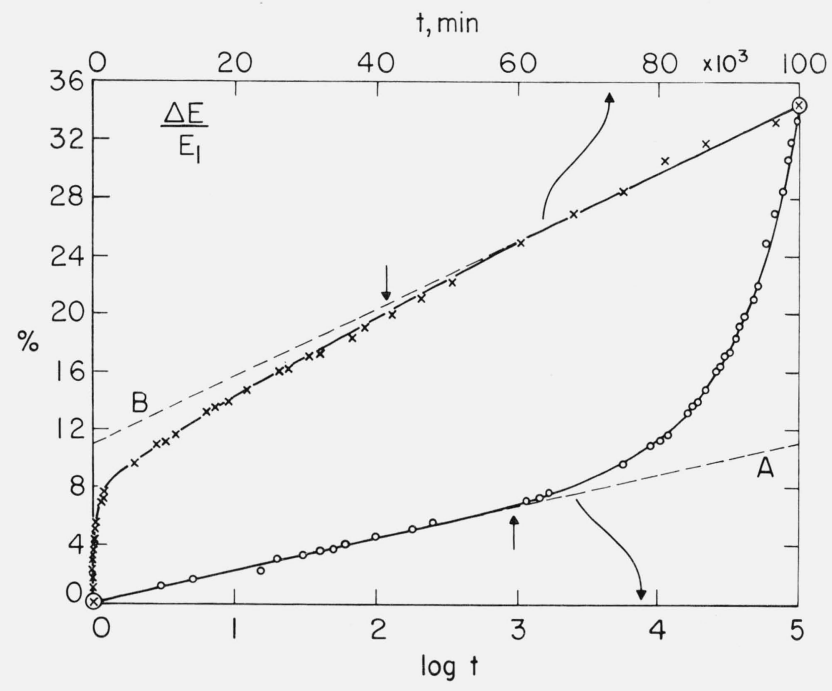

FIGURE 1.-Double-abscissa plot of experimental values of fractional change in elongation of specimen $B$ (dry air atmosphere) as a function of $\log \mathrm{t}$ (lower curve, lower scale) and also as a function of $\mathrm{t}$ (upper curve, upper abscissa scale).

Scales coincide at $t=1$ and $t=100,000 \mathrm{~min}$. Both curves represent the equation

$$
\Delta E / E_{1}=2.239 \log t+23.59 \times 10^{-5}(t-1)
$$

where $t$ is in minutes and $\Delta E / E_{1}$ in percent. Lower dashed straight line has the slope $A=$ 2.239 percent/(unit $\log t)$. Upper dashed straight line has the slope $B=23.59 \times 10^{-5}$ percent/ $\mathrm{min}$. Vertical arrows mark the limits of approximate linearity given in table 2 .

tional change in elongation $\Delta E / E_{1}$ is given as a function of $\log t$ (lower curve, lower abscissa scale) and also as a function of $t$ (upper curve, upper abscissa scale). A comparison of the two scales is made by noting the two abscissa values corresponding to any given ordinate. In figure 1 the scales are made to coincide at $t=1 \mathrm{~min}(\log t=0)$ and at $t=100,000 \mathrm{~min}$ ( $\log t=5$ ). Consequently the two curves must intersect at these points whatever the nature of the function $\Delta E / E_{1}$.

It can be seen in figure 1 that in dry air the creep, measured as the observed fractional change in elongation $\Delta E / E_{1}$, is linear with $\log t$ over an extended region up to about 1000 min and linear with $t$ beyond about $40,000 \mathrm{~min}$. In the intermediate region both lines are curved.

Double-abscissa plots for specimens A and D were qualitatively similar to that shown in figure 1 for 
Specimen B. The plot for Specimen C in room air at 35 percent humidity was similar in all respects except that it showed much larger values of $\Delta E / E_{1}$ at all times with an increasing deviation from the linear relation for values of $t$ above about $50,000 \mathrm{~min}$. At 86,658 $\mathrm{min}$ the observed value of $\Delta E / E_{1}$ was about 154 percent as contrasted with 125 percent obtained by linear extrapolation. In contrast with the other specimens also, Specimen C broke after being stretched for about $90,000 \mathrm{~min}$ whereas the other three specimens were still intact when they were unloaded at about 100,000 $\min$.

\section{Equation for Representing Creep as a Function of Time}

All the data obtained in the present studies, except for the anomalous increase in the creep of Specimen $\mathrm{C}$ after $50,000 \mathrm{~min}$, could be well represented by an equation of the following form:

$$
\Delta E / E_{1}=A \log t+B(t-1)
$$

where $A$ and $B$ are independent of time. The two solid curves in figure 1 are drawn to represent this equation, with the constants $A=2.239$ percent/(unit $\log t)$ and $B=23.59 \times 10^{-5}$ percent $/ \mathrm{min}$. The observed values of $\Delta E / E_{1}$ lie close to those given by the equation, as can be seen from the experimental points plotted in figure 1 and similar plots for the other specimens. The only serious deviation is that already mentioned for Specimen $\mathrm{C}$ just before it broke.

The predicted slopes of the two curves are obtained by differentiation of eq (5.1)

$$
\begin{gathered}
\frac{\partial}{\partial \log t}\left(\frac{\Delta E}{E_{1}}\right)=A+B t \\
\frac{\partial}{\partial t}\left(\frac{\Delta E}{E_{1}}\right)=0.4343 A / t+B
\end{gathered}
$$

It can be seen that the values given by eq (5.2) approach the constant $A$ as $t$ is reduced, while those given by eq (5.3) approach the constant $B$ as $t$ is increased. This behavior is apparent in figure 1 , which includes straight lines drawn with these slopes.

In quantitative terms, as $t$ increased, $\frac{\partial}{\partial \log t}\left(\frac{\Delta E}{E_{1}}\right)$ is equal to $A$ initially and becomes 10 percent greater than $A$ when

$$
t=0.1(A / B)
$$

On further increase of $t \frac{\partial}{\partial t}\left(\frac{\Delta E}{E_{1}}\right)$ decreases to a value only 10 percent greater than $B$ when

$$
t=4.343(A / B)
$$

Beyond this point the slope approaches $B$ asymptotically.

The two constants $A$ and $B$ in eq (5.1) can be evaluated by solving two simultaneous equations obtained from two of the observations. In our work the constants have been obtained from only two observed values of $\Delta E / E_{1}$, one where $\log t$ was about 5 and the other where it was about 3 . Thus in future work, unless the validity of the form of eq (5.1) is doubted, only two observations need be made, in addition to the 1-min value. It would seem best of course to make use of the creep at the longest time for one observation. The constants obtained in the present study depended very little on which intermediate time was chosen for the second observation.

The numerical results obtained in our work are given in table 2. After the constants $A$ and $B$ had been evaluated, the curves were drawn to represent eq (5.1). The ratio $(A / B)$ was then used in eqs (5.4) and (5.5) to determine the remaining quantities in table 2 . This procedure is regarded as more precise and accurate than a determination of these quantities directly from the graphs. The quantities in the last three lines of table 2 indicate the approximate boundaries of the linear relations. For example, for Specimen B the lower curve in figure 1 is regarded as approximately linear up to the point where $\log t=2.98$ (namely where $t=949 \mathrm{~min})$ and the upper curve becomes approximately linear after a time $t=41,200 \mathrm{~min}$. These abscissas are marked with vertical arrows in figure 1 . In the intermediate region both lines are curved. It can be noted that variations in the ratio $A / B$ are chiefly due to variations in $B$, and that large values of $B$ lead to small values of time marking the boundary regions.

\section{Discussion}

An examination of the data in tables 1 and 2 shows that the substitution of nitrogen for air (with the elimination of oxygen) in the atmosphere caused no change in the 1-min modulus and very little change in the value of the constant $\boldsymbol{A}$. Essentially the same value of this quantity was found in an independent experiment in which the glass tube was evacuated instead of being filled with nitrogen.

On the other hand the slope of the curve in the longtime region, where it is nearly linear with time, was increased tenfold by the presence of air.

An increase of humidity in the air produced a slight progressive decrease in 1-min modulus and a moderate progressive increase in the value of the constant $A$. The value of the constant $B$, the slope of the curve in the long-time region increased considerably with increase of humidity. Specimen C-where the relative humidity was 35 percent and there was no circulation of air around the specimen - was anomalous in several respects. The constant $B$ was even larger than that 
TABLE 2

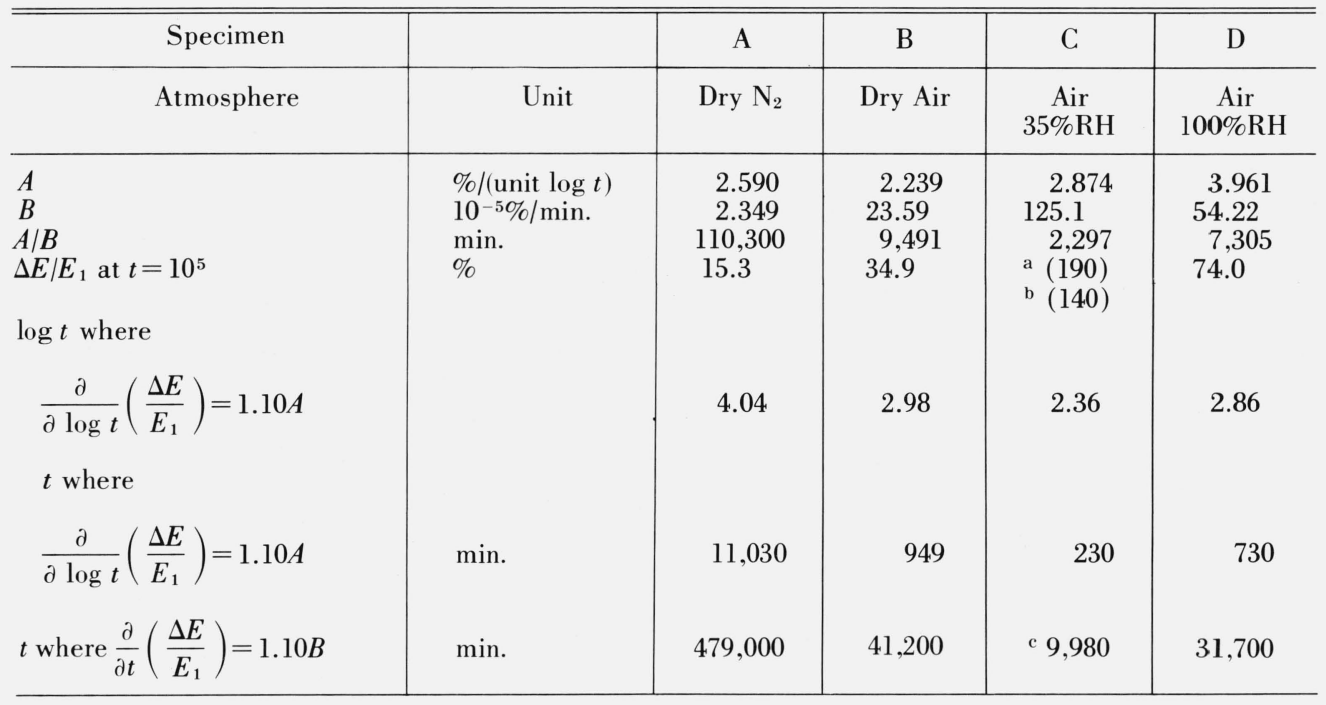

\footnotetext{
a Extrapolated from observed values.

${ }^{b}$ Extrapolated from linear relation.

${ }^{\mathrm{c}}$ Linear relation not followed beyond $t=50,000 \mathrm{~min}$.
}

for Specimen D, where the air was bubbled through water to produce a relative humidity of 100 percent. Furthermore the linear relation for Specimen C was followed only from about 10,000 to $50,000 \mathrm{~min}$ and the specimen broke after about $90,000 \mathrm{~min}$.

Further work would be desirable to ascertain the cause of this anomalous behavior. It is quite likely that the stagnant air surrounding Specimen C contained substances capable of accelerating the degradation of the rubber. These might be products of the degradation reaction exerting an autocatalytic effect on the reaction, or they might include ozone from the air of the room, which was illuminated by fluorescent lamps. On the other hand, with Specimens A, B, and $\mathrm{D}$, which were surrounded by an atmosphere of nitrogen or air which had been passed over $\mathrm{CaCl}_{2}$ or bubbled through water, the forced circulation removed the accelerating substances from contact with the specimens.

The form of eq (5.1) indicates that there are two different processes leading to creep. The first is predominant at short times, is fully recoverable, and is characterized by the value of the constant $A$. The second is predominant at long times, may be only partially recoverable, and is characterized by the value of the constant $B$.

Both processes are effective throughout the whole range of time, and the boundaries of the regions of predominance are characterized by the values of the ratio $A / B$ as can be seen from eqs (5.4) and (5.5). It can be seen from the values given in table 2 that there is an extensive intermediate region where neither process predominates. Here one arbitrarily defines the boundaries of the region as those where the respective slopes differ by more than 10 percent from their limiting values. With this definition, one finds that the time increases by a factor of 43.43 in this region. The experimental values of $\Delta E / E_{1}$ are in good agreement with the equation throughout this region as well as in the regions where one process or the other is predominant. The existence of this intermediate region has not been explicitly recognized in previous work.

\section{Comparison With Previous Investigations}

The form of creep relation shown by eq (5.1) is apparently very general. It has been applied to many amorphous and polycrystalline solids of widely different molecular structures. Lyons [5] has claimed that it is representative of all normal creep (except at high stresses near the breaking load). He gives a comprehensive historical summary of its use for many materials and in his own work applied it to the creep of tire cords. However, Findley [6, 7] considers that the creep of plastics is better represented in terms of an equation containing the time raised to a positive fractional power.

The application of eq (5.1) to rubber has been quite limited. Derham, Lake, and Thomas [8] have found it applicable to a rubber vulcanizate at $70{ }^{\circ} \mathrm{C}$. They consider the parameter $A$ to represent the physical component of the creep and the parameter $B$ to represent the chemical component. The values they reported were $A=1.82$ percent/(unit $\log t$ ) and $B=346 \times 10^{-5}$ percent $/ \mathrm{min}$.

In many instances the time of observation of the creep in rubber has been so short that the only region noted has been the "primary creep" region, in which 
the fractional creep is proportional to the logarithm of the time [9-15]. In other work [3, 16, 17] the rise above the line has been noted at the longer times, especially at $70{ }^{\circ} \mathrm{C}$ or higher temperatures. It has usually been denoted as "secondary creep," without any quantitative evaluation, such as that which we have given here in terms of the constant $B$. A striking advance in this respect was made by Gent [18]. In a comprehensive study, he obtained values of the secondary creep by subtracting the primary creep from the observed creep. He reported observations extending up to 15,000 min showing that the secondary creep in most cases was linear with time. This is in accordance with eq (5.1) and yielded values of $B$ ranging from $50 \times 10^{-5}$ to $140 \times 10^{-5}$ percent $/ \mathrm{min}$ at $60^{\circ} \mathrm{C}$.

Our own previous studies $[2,19]$ of compliance, as measured by indentation, showed a region of linearity of compliance at $25{ }^{\circ} \mathrm{C}$ with $\log t$ over a range of about 6 decades of $\log t-3$ of them below 1 min and 3 of them above. At the shortest times, the values fell below the line because of the approach to the glass transition. At the longest times, the values rose higher and higher above the line. The slope of the line corresponded to a change of 2 percent/(unit $\log t)$ in reasonable agreement with the values of $A$ given in table 2 . Our previous work involved time-temperature equivalence of course, unlike the present constant temperature studies, which involved no observations at times of less than $1 \mathrm{~min}$. However Wildschut [20] and Brenschede [9] have reported the results of direct recovery measurements at room temperature indicating a linearity of recovery with $\log t$ to times as short as about $6 \mathrm{~ms}-$ at which point inertial effects appeared. Brenschede's results showed linearity with $\log t$ to values as high as $10,000 \mathrm{~s}$, a range of about 6 decades of logarithmic time.

We have noted only three instances [21-23] in the literature where the creep near room temperature has been plotted with time as the abscissa for times longer than $10,000 \mathrm{~min}$, so that $B$ could be evaluated. In all three cases there was a range over which $B$ was approximately constant.

The work of Braun [21] on stretched rubber bands at $27{ }^{\circ} \mathrm{C}$ showed the expected initial linearity of creep with $\log t$ with a slope of 3-4 percent/(unit $\log t$ ). When plotted against $t$, the creep showed the expected region of rapid rise followed by a region of approximate linearity with time. Here for elongations in the range 220 to 280 percent with fractional creep values of 27-55 percent a value of $B$ of about $15 \times 10^{-5}$ percent $/ \mathrm{min}$ could be calculated. Finally Braun found a region of more rapid rise beginning at 120-200 days (depending on the tension) and terminating in rupture in about 240 days.

Our present work extending to about 70 days included only one case of rupture, namely Specimen C, which broke in about 63 days $(90,000 \mathrm{~min})$, following a pre-rupture rapid increase of creep.

The second long-time creep study was that of Mooney, Wolstenholme, and Villars [22] who followed the compression creep of several thick rubber vulcanizates for 3000 days $\left(4.3 \times 10^{6} \mathrm{~min}\right)$. After the initial rise, the compression creep at $35^{\circ} \mathrm{C}$ showed linearity with time with a slope corresponding in one instance to a value of $B=4 . \times 10^{-5}$ percent $/ \mathrm{min}$.

Linnig, Parks, and Stiehler [23] followed the creep of a stretched pure-gum rubber vulcanizate for about $56,000 \mathrm{~min}$. The only previous workers to present their results in a double-abscissa plot like figure 1, they show data from which one can calculate that $A=2.12$ percent/(unit $\log t)$ and $B=306 \times 10^{-5}$ percent $/ \mathrm{min}$ at $50{ }^{\circ} \mathrm{C}$. They state that the change from linearity on a log-time scale to linearity on a uniform time scale occurred at about $1500 \mathrm{~min}$ at $50{ }^{\circ} \mathrm{C}$, sooner at $70{ }^{\circ} \mathrm{C}$, and later at $24{ }^{\circ} \mathrm{C}$. Their results were not given in sufficient detail to make obvious the intermediate region where neither plot is linear, as already noted in the present studies.

The increase of the constant $A$ with humidity would be anticipated from the results of Derham and coworkers $[4,8,24]$ who found that the stress relaxation at $25{ }^{\circ} \mathrm{C}$ was almost linear with $\log t$. The slope increased from about 1.6 percent/(unit $\log t)$ when the relative humidity was 15 percent to about 2.5 percent/(unit $\log t)$ at 92 percent relative humidity [8]. In other work [4] it increased from 2 percent/unit log $t$ at 15 percent relative humidity to 3.4 percent/unit $\log t$ at 100 percent humidity. These values may be compared with those obtained for the constant $A$ in the present work.

Derham and co-workers $[8,24]$ have reported values of a quantity corresponding to the constant $B$ (denoted as the "chemical creep rate") at temperatures of $50,60,70$, and $80^{\circ} \mathrm{C}$. The observed values of $B$ ranged from near $10 \times 10^{-5}$ percent $/ \mathrm{min}$ at $50^{\circ} \mathrm{C}$ to more than $1000 \times 10^{-5}$ percent $/ \mathrm{min}$ at $80^{\circ} \mathrm{C}$. When $\log B$ is plotted against $T^{-1}$, the reciprocal of the temperature in kelvins, straight lines are obtained, corresponding to activation energies of 20-30 kcal/mol (85-125 kJ/mol), the values depending on the vulcanizing system, particularly the amount of antioxidant. It is considered significant that an activation energy of $30 \mathrm{kcal} / \mathrm{mol}$ corresponding to oxidative chain scission has been previously reported, as calculated from the observations of stress relaxation of a natural rubber vulcanizate at 100 to $130{ }^{\circ} \mathrm{C}$ by Tobolsky, Dillon, and Prettyman [25-27].

We have not found values for the change of the constant $A$ with temperature. The change is certainly small [24] and is probably a decrease with increase of temperature. Gent [18] has reported observations indicating that $A$ is slightly smaller at $60{ }^{\circ} \mathrm{C}$ than at $23^{\circ} \mathrm{C}$. The same behavior can be noted in results for GR-I (Butyl rubber) given by Martin, Roth, and Stiehler [3].

The present discussion has been limited to natural rubber cured with conventional sulfur-accelerator recipes. The creep behavior of natural rubber crosslinked by peroxides has not been considered. In the latter case the studies of Thirion and Chasset [28-30] over about 4 decades of $\log$ time have shown that the rate of stress relaxation at temperatures below $65{ }^{\circ} \mathrm{C}$ decreases with increase of time. This was confirmed by Steiner and Tobolsky [31], but the range of only 2 
decades in our own work [32] with peroxide-crosslinked rubbers was not sufficiently extended to show a decrease. In terms of the quantities used here, this is equivalent to a decrease of $A$ with time. For conventional vulcanizates however, at temperatures well above the glass transition temperature we have found no evidence of such a decrease in our work $[2,19]$ or in the literature.

\section{Conclusions}

The long-time creep of natural rubber cured with a conventional sulfur-accelerator recipe containing no filler can be conveniently shown near room temperature by a plot of $\Delta E / E_{1}$ with a double-abscissa scaleone marked in units of $\log t$ and the other in units of $t$. When experimental data from the present work and from previous studies reported in the literature are plotted in this manner it is noted that invariably the first scale yields a linear relation at short times and the second a linear relation at long times.

The limiting linear relations just mentioned suggest the two-constant equation

$$
\Delta E / E_{1}=A \log t+B(t-1)
$$

already proposed as a general creep equation for many materials. In the case of rubber the range of values of $t$ investigated is from about $10 \mathrm{~ms}$ as studied by previous investigators to about 70 days in our work and other studies. Any significant deviations from the equation can be noted by inspection of the double-abscissa plot. We found that the equation furnished an excellent representation of almost all our experimental data up to the longest times. In one instance in our work and in a few other cases there was a pre-rupture increase of $\Delta E / E_{1}$ above the values given by the equation. This behavior can reduce somewhat the upper limit of validity of the general equation.

The constants $A$ and $B$ can be evaluated from experimental observations of $\Delta E / E_{1}$ by solving two simultaneous equations obtained from values at the longest time, at one minute, and at an intermediate time.

In the present work, the constant $A$ was essentially the same [about 2.4 percent/(unit $\log t)$ ] when the atmosphere surrounding the specimen was a vacuum, dry nitrogen, or dry air. The value was raised when the atmosphere was room air at 35 percent relative humidity and became about 4 percent/(unit $\log t$ ) when the air was saturated with water.

The constant $B$ was raised tenfold when the atmosphere was dry air instead of dry nitrogen. It was further increased by a factor of about 2 , when the air was saturated. The value of $B$ for the specimen in an atmosphere of stagnant room air was still greater than this by another factor of more than 2 . It is possible that this atmosphere contained autocatalytic degradation products or other constituents which were removed when the air was bubbled through water or passed over $\mathrm{CaCl}_{2}$.

The approximate boundaries of three different regions of time are determinable from the ratios $A / B$.
In the first region where $t$ is less than $0.1(A / B) \Delta E / E_{1}$ is approximately linear with $\log t$. In the second region, where $t$ is between $0.1(A / B)$ and $4.343(A / B), \Delta E / E_{1}$ is not linear with either $\log t$ or $t$. In the third region, where $t$ is greater than $4.343(A / B), \Delta E / E_{1}$ is approximately linear with $t$. A fourth region of anomalous increase preceding rupture is sometimes found, especially when $B$ is large.

The creep process characterized by the constant $A$ appears to be a physical process [14] continuing indefinitely but becoming of diminishing importance relative to the creep process characterized by the constant $B$. For most conventional pure-gum natural rubber vulcanizates $A$ has a value of $2-4$ percent/(unit $\log t)$. The process characterized by $B$ is effective from the beginning but its relative importance increases until it finally predominates. It is probably associated with a chemical change, presumably oxidative degradation of the rubber network [18]. However any process which is proportional to the time under stress would be included. The values of $B$ ranged from $2 \times 10^{-5}$ to $125 \times 10^{-5}$ percent $/ \mathrm{min}$ in our work. The values were increased considerably by the presence of oxygen and water in the atmosphere surrounding the stretched specimen. The work of others $[24,26]$ has shown that the change of $B$ with temperature corresponds to an activation energy of $20-30 \mathrm{kcal} / \mathrm{mol}(85-125 \mathrm{~kJ} / \mathrm{mol})$. The value of $A$ probably decreases slightly with increase of temperature [3, 18].

There are many interesting possibilities for the application of this type of analysis to a study of the effect of other variables on long-time creep. One of these would involve the effect of temperature on the constants $A$ and $B$. Another study could well be an investigation of the anomalous pre-rupture creep already mentioned. The long-time creep of rubber cross-linked with dicumyl peroxide might well be studied to determine the behavior of the constant $B$ as the constant $A$ is made smaller and smaller by increased cross-linking [32]. Finally it would be of interest to evaluate $A$ and $B$ for various types of synthetic rubber.

\section{References}

[1] Wood, L. A., and Roth, F. L., Creep of pure-gum rubber vulcanizates from indentation-time measurements, Proc. 4th Rubber Technol. Conf. London 1962 p. 328. Institution of Rubber Industry London 1963, Rubber Chem. Technol. 36,611 (1963).

[2] Roth, Frank L., Bullman, George W., and Wood, Lawrence A., Compliance-time-temperature relationships from indentation measurements on a pure-gum rubber vulcanizate, J. Res. Nat. Bur. Stand. (U.S.), 69A (Phys. and Chem.), No. 4, 347-353 (July-Aug. 1965).

[3] Martin, G. M., Roth, F. L., and Stiehler, R. D., Behavior of "pure gum" rubber vulcanizates in tension, Trans. Inst. Rubber Ind. 32, 189 (1956), Rubber Chem. Technol. 30, 876 (1957).

[4] Derham, C. J., Effect of moisture on the creep and stress relaxation of natural and synthetic general purpose rubbers. Internat. Rubber Conference, Brighton, England, May 1972 Fl-1.

[5] Lyons, W. J., The general relations for flow in solnds and their application to the plastic behavior of tire cords, J. Applied Phys. 17, 472 (1946).

[6] Findley, W. N., Creep characteristics of plastics, p. 118 A.S.T.M. Symposium on Plastics, Philadelphia 1944; American Society for Testing Materials, Philadelphia 1944. 
[7] Findley, W. N., Mechanism and mechanics of creep in plastics, SPE Journal 16,57 and 192 (1960).

[8] Derham, C. J., Lake, G. J., and Thomas A. G., Some factors affecting the service life of natural rubber articles, J. Rubber Res. Inst. Malaya 22, 191 (1969).

[9] Brenschede, W., Deformation mechanics of rubberlike bodies. Extension of concepts of the kinetics of rubber elasticity, Kolloid-Zeits 104, 1 (1943).

[10] Wildschut, A. J., Pseudo-Plastic phenomena with vulcanized rubber, Physica 10,571 (1943); Rubber Chem. Technol. 17, 845 (1944).

[11] Throdahl, M. C., Aging of elastomers. Comparison of creep with some conventional aging methods, Ind. Eng. Chem. 40, 2180 (1948); Rubber Chem. Technol. 22, 699 (1949).

[12] Cooper, D. H., Primary creep and stiffness of vulcanized rubber, Ind. Eng. Chem. 43, 365 (1951); Rubber Chem. Technol. 24, 621 (1951).

[13] Bueche, F., Mechanical properties of natural and synthetic rubbers, J. Polymer Sci. 25, 305 (1957); Rubber Chem. Technol. 31, l (1958).

[14] A. N. Gent, Relaxation processes in vulcanized rubber, I. Relation among stress relaxation creep, recovery, and hysteresis, J. Applied Polymer Sci. 6, 433 (1962). Rubber Chem. Technol. 36, 377 (1963).

[15] Farlie, E. D., Creep and stress relaxation of natural rubber vulcanizates. I. Effect of cross-link density on the rate of creep in different vulcanizing systems, J. Applied Polymer Sci. 14, 1127 (1970) Rubber Chem. Technol. 44, 707 (1971).

[16] Hahn, Stuart H., and Gazdik, I., Creep of natural and synthetic rubber compounds in shear, India Rubber World 103 (5), 51 (1941); Rubber Chem. Technol. 14, 433 (1941).

[17] Gehman, S. D., Creep, recovery, and permanent set for GR-S and Hevea, J. Applied Phys. 19, 456 (1948); Rubber Chem. Technol. 22, 105 (1949).

[18] Gent, A. N., Relaxation processes in vulcanized rubber. II. Secondary relaxation due to network breakdown, J. Applied Polymer Sci. 6, 442 (1962). Rubber Chem. Technol. 36, 389 (1963).

[19] Wood, Lawrence A., Creep of pure-gum vulcanizates of natural rubber, J. Rubber Res. Inst. Malaya 22, 309 (1969); Rubber Chem. Technol. 43, 1482 (1970).

[20] Wildschut, A. J., "Technological and Physical Investigations on Natural and synthetic rubbers," Chapter V, Elsevier Publishing Co., New York (1946).

[21] Braun, Milton L., A preliminary study of the after-effect or drift in rubber under constant load, Physics 7, 421 (1936); Rubber Chem. Technol. 10,224 (1937).
[22] Mooney, M., Wolstenholme, W. E., and Villars, D. S., Drift and relaxation of rubber, J. Applied Phys. 15, 324 (1944); Rubber Chem. Technol. 1 7, 576 (1944).

[23] Linnig, Frederic J., Parks, Edwin J., and Stiehler, Robert D., Effect of certain crystalline substances on physical properties of elastomers. I. Stress-strain behavior, Rubber Chem. Technol. 39, 1041 (1966).

[24] Derham, C. J., Southern, E., and Thomas A. G., Some factors affecting the life of rubber articles in service, Internat Rubber Conference, Moscow, Nov. 1969; NRPRA Rubber Technol. Rubber Develop. Supplement No. 7 (1970). Derham, C. J., Creep and stress relaxation of rubbers - the effect of stress history and temperature changes, J. Materials Sci. 8, 1023 (1973).

[25] Tobolsky, A. V., Prettyman, I. B., and Dillon, J. H., Stress re laxation of natural and synthetic rubber stocks, J. Applied Phys. 15, 380 (1944) Rubber Chem. Technol 17, 551 (1944).

[26] Tobolsky, A. V., Properties and Structures of Polymers, John Wiley \& Sons, New York, 1960, p. 223.

[27] Bartenev, G. M., Relaxation properties of polymers at various levels of molecular and supramolecular organization. Stress relaxation mechanisms in elastomers. Relaksatsionnye Yavleniya Polim, 1972 249-61 (Russ). Edited by G. M. Bartenev, Khimiya, Leningrad OtD.

[28] Thirion, P., and Chasset, R., Relative contributions of viscoelasticity and ageing to the relaxation of rubber vulcanizates, Proc. 4th Rubber Tech. Conf. London 1962. T. H. Messenger, Ed. p. 338 (Inst. Rubber Ind. London 1963) Rev. Gen. Caout chouc 41, 271 (1964); Rubber Chem. Technol. 36, 50 (1963).

[29] Chasset, R., and Thirion, P., Viscoelastic relaxation of rubber vulcanizates between the glass transition and equilibrium. Proc. Int. Conf. Non-crystalline Solids Delft 1964; J. A. Prins Ed. p. 345. North-Holland Publishing Co., Amsterdam. Interscience Publishers, New York; Rubber Chem. Technol. 39, 870 (1966), Rev. Gen Caoutchouc 44, 1041 (1967).

[30] Chasset, R., and Thirion, P., Delayed elasticity of pure-gum rubber vulcanizates, J. Rubber Res. Inst. Malaya 22, 331 (1969).

[31] Steiner, G., and Tobolsky, A. V., A note on stress relaxation of rubber networks in the vicinity of room temperature, Rubber Chem. Technol. 43, 1036 (1970).

[32] Wood, Lawrence A., and Bullman, George W., Creep and other properties of rubber cross-linked by dicumyl peroxide, J. Polymer Sci. A-2, 10, 43 (1972).

(Paper 78A5-837) 